\title{
The AACES field experiments: SMOS calibration and validation across the Murrumbidgee River catchment
}

\author{
S. Peischl ${ }^{1, *}$, J. P. Walker ${ }^{1, *}$, C. Rüdiger ${ }^{1, *}$, N. Ye ${ }^{1, *}$, Y. H. Kerr ${ }^{2}$, E. Kim ${ }^{3}$, R. Bandara ${ }^{1, *}$, and M. Allahmoradi ${ }^{4}$ \\ ${ }^{1}$ Monash University, Department of Civil Engineering, Melbourne, Australia \\ ${ }^{2}$ Centre d'Etudes Spatiales de la Biosphére (CESBIO), Toulouse, France \\ ${ }^{3}$ Goddard Space Flight Center, NASA, Hydrospheric and Biospheric Sciences Laboratory, Greenbelt, USA \\ ${ }^{4}$ The University of Melbourne, Department of Infrastructure Engineering, Melbourne, Australia \\ * formerly at: The University of Melbourne, Department of Infrastructure Engineering, Melbourne, Australia
}

Correspondence to: S. Peischl (sandy.peischl@monash.edu)

Received: 17 February 2012 - Published in Hydrol. Earth Syst. Sci. Discuss.: 2 March 2012

Revised: 18 May 2012 - Accepted: 23 May 2012 - Published: 22 June 2012

\begin{abstract}
Following the launch of the European Space Agency's Soil Moisture and Ocean Salinity (SMOS) mission on 2 November 2009, SMOS soil moisture products need to be rigorously validated at the satellite's approximately $45 \mathrm{~km}$ scale and disaggregation techniques for producing maps with finer resolutions tested. The Australian Airborne Cal/val Experiments for SMOS (AACES) provide the basis for one of the most comprehensive assessments of SMOS data worldwide by covering a range of topographic, climatic and land surface variability within an approximately $500 \times 100 \mathrm{~km}^{2}$ study area, located in South-East Australia. The AACES calibration and validation activities consisted of two extensive field experiments which were undertaken across the Murrumbidgee River catchment during the Australian summer and winter season of 2010, respectively. The datasets include airborne L-band brightness temperature, thermal infrared and multi-spectral observations at $1 \mathrm{~km}$ resolution, as well as extensive ground measurements of near-surface soil moisture and ancillary data, such as soil temperature, soil texture, surface roughness, vegetation water content, dew amount, leaf area index and spectral characteristics of the vegetation. This paper explains the design and data collection strategy of the airborne and ground component of the two AACES campaigns and presents a preliminary analysis of the field measurements including the application and performance of the SMOS core retrieval model on the diverse land surface conditions captured by the experiments. The data described in this paper are publicly available from the website: http://www.moisturemap.monash.edu.au/aaces.
\end{abstract}

\section{Introduction}

In May 1999, the Soil Moisture and Ocean Salinity (SMOS) concept was selected as the second Earth Explorer Opportunity mission by the European Space Agency (ESA), with SMOS aiming at dedicated space borne observations of two crucial environmental variables: soil moisture and sea surface salinity (Kerr et al., 2001). Ten years later on 2 November 2009, the SMOS satellite was launched successfully into a heliosynchronous orbit $(758 \mathrm{~km}$ altitude) with a mean local solar time overpass of 06:00 a.m. at the ascending node (Barré et al., 2008). The single SMOS payload is the Microwave Imaging Radiometer with Aperture Synthesis (MIRAS) operating in the protected L-band at 1.400-1.427 GHz. The SMOS mission targets for soil moisture observations are (i) a product accuracy of $0.04 \mathrm{~m}^{3} \mathrm{~m}^{-3}$ or better over bare soil and low vegetated areas, defined as biomass having an integrated vegetation water content of less than $5 \mathrm{~kg} \mathrm{~m}^{-2}$, (ii) a revisit time of at least every three days at approximately 06:00 a.m. LST (local solar time), and (iii) a spatial resolution of preferably less than $45 \mathrm{~km}$, with the latter being addressed by simulating a large antenna size using interferometric aperture synthesis (Kerr et al., 2010).

This innovative two-dimensional Y-shaped radiometer and the novel interferometric antenna concept represent a new generation technology, which requires comprehensive testing for both the SMOS brightness temperature measurements and the retrieved soil moisture products. The validation approach chosen for the land component of SMOS relies on 
the extensive usage of ground and aircraft data, that preferably capture a broad range of topography, climate, land cover and vegetation types. Consequently, numerous locations distributed across the world have been selected for that purpose: for instance the Antarctic plateau DOME C, the French Mauzac site near Toulouse, and ESA's two core validations sites: (i) the Valencia Anchor Station located in the East of Spain and (ii) the Upper Danube Catchment in Southern Germany (Delwart et al., 2008; Mecklenburg et al., 2009). Moreover, permanent soil moisture measurements obtained from long-term monitoring stations provide an additional basis for world-wide validation activities. The International Soil Moisture Network (ISMN) has been established to serve as a platform making station data available (Dorigo et al., 2011). Given the large $45 \mathrm{~km}$ SMOS footprint and the inherent heterogeneity in topography and land cover, a representative in situ sampling strategy needs to be considered for a sophisticated analysis of the SMOS models and products.

The focus of the European experimental sites is limited to a single SMOS pixel and/or a single airborne transect through several SMOS pixels, with repeat flights over a given time period: e.g., SMOSREX (de Rosnay et al., 2006), MELBEX (Cano et al., 2008, 2010), and EuroSTARRS (Saleh et al., 2004). In contrast, the field campaigns described in this paper, named Australian Airborne $\mathrm{Cal} / \mathrm{val}$ Experiments for SMOS (AACES), were designed to provide an extensive validation dataset by completely covering a minimum of 20 independent ( $\approx 40$ overlapping) SMOS pixels, which correspond to a study area of approximately $50000 \mathrm{~km}^{2}$ (Fig. 1). The range of topographic, climatic and land cover conditions captured within the AACES study area is not only typical of Australia, but also across the world, thus, making it an excellent validation site for the soil moisture component of the SMOS satellite mission. Moreover, the existing long-term soil moisture network together with the variability in natural features across the study area means this experimental site has also been the focus of several other extensive campaigns: (i) the National Airborne Field Experiment (NAFE) in 2006, that monitored and sampled a single SMOS pixel over three weeks (Merlin et al., 2008) and (ii) the Soil Moisture Active and Passive Experiments (SMAPex) (Panciera et al., 2012), conducted in support of the planned Soil Moisture ActivePassive (SMAP) mission led by the National Aeronautics and Space Administration (NASA), that will combine an active and passive microwave system to provide a $10 \mathrm{~km}$ soil moisture product.

The AACES experiment comprises a set of two separate field campaigns which each combined extensive airborne and ground based data collection across the Murrumbidgee River catchment in 2010. While AACES- 1 took place from 18 January to 21 February 2010 (5 weeks), capturing the Australian summer conditions, AACES-2 was performed during the Australian winter from 8-26 September 2010 (3 weeks). This paper describes the general objectives of the AACES field experiments, along with the airborne and ground data collected during both AACES- 1 and AACES- 2 campaigns. A brief overview of the study area, the reasoning of the experimental strategy and a summary together with a preliminary analysis of the datasets are presented. The detailed sampling protocols for all airborne and ground activities are given in the respective field experiment plan of each AACES campaign (see Walker et al., 2010a,b).

\section{Study area description}

The AACES field experiments were undertaken across an approximate $500 \times 100 \mathrm{~km}^{2}$ study area within the Murrumbidgee River catchment $\left(-33^{\circ}\right.$ to $-37^{\circ} \mathrm{S}$ and $143^{\circ}$ to $150^{\circ} \mathrm{E}$ ), which forms the southern part of the Murray Darling Basin in south-eastern Australia (Fig. 1). The Murrumbidgee River catchment comprises of about $82000 \mathrm{~km}^{2}$, ranging from elevations as low as $50 \mathrm{~m}$ in the West to around $2000 \mathrm{~m}$ in the East (Geoscience Australia, 2008), as presented in Fig. 2. Together with the broad variation in topography, the climate conditions change from semi-arid climate in the flat, clay-loam dominated western plains, to alpine conditions in the mountainous areas with coarse-textured sandy soils (McKenzie et al., 2000). The average annual rainfall varies from $300 \mathrm{~mm}$ in the West to $1900 \mathrm{~mm}$ in the high elevated ranges (Australian Bureau of Rural Science, 2001). However, in the eastern alpine region only half of the precipitated water is evapotranspired, whereas in the dry flat western areas of the catchment the actual evaporation rate is similar to the total amount of rain received. During the Southern Hemisphere winter season the eastern areas with elevations above $1200 \mathrm{~m}$ typically experience precipitation in the form of snow, with a temporary snow cover of up to a few weeks for regions above $1400 \mathrm{~m}$. Areas above $1800 \mathrm{~m}$ are usually covered by snow for four months or more (Whetton et al., 1996). Due to the natural conditions, land use in the Murrumbidgee River catchment is primarily characterised by agriculture and livestock farming (Fig. 2). Extensive grazing areas dominate the wide western plains, whereas broad-acre cropping and agriculture with irrigation districts is more common in the central region. The (very) eastern regions mainly consist of conservation areas and state forests (Australian Bureau of Rural Science, 2006). Note that while there was no snow cover in the study area during AACES-1 and AACES-2, there was snow in the alpine region. Consequently, an additional flight was undertaken during AACES-2 coincident with ground sampling activities, to provide an opportunity to also assess the impact of snow on SMOS.

\section{Airborne data description}

The AACES- 1 summer campaign in January 2010 focused on the entire $50000 \mathrm{~km}^{2}$ transect outlined in Fig. 1. The subsequent AACES-2 winter campaign in September 2010 was reduced in terms of spatial coverage and ground sampling 


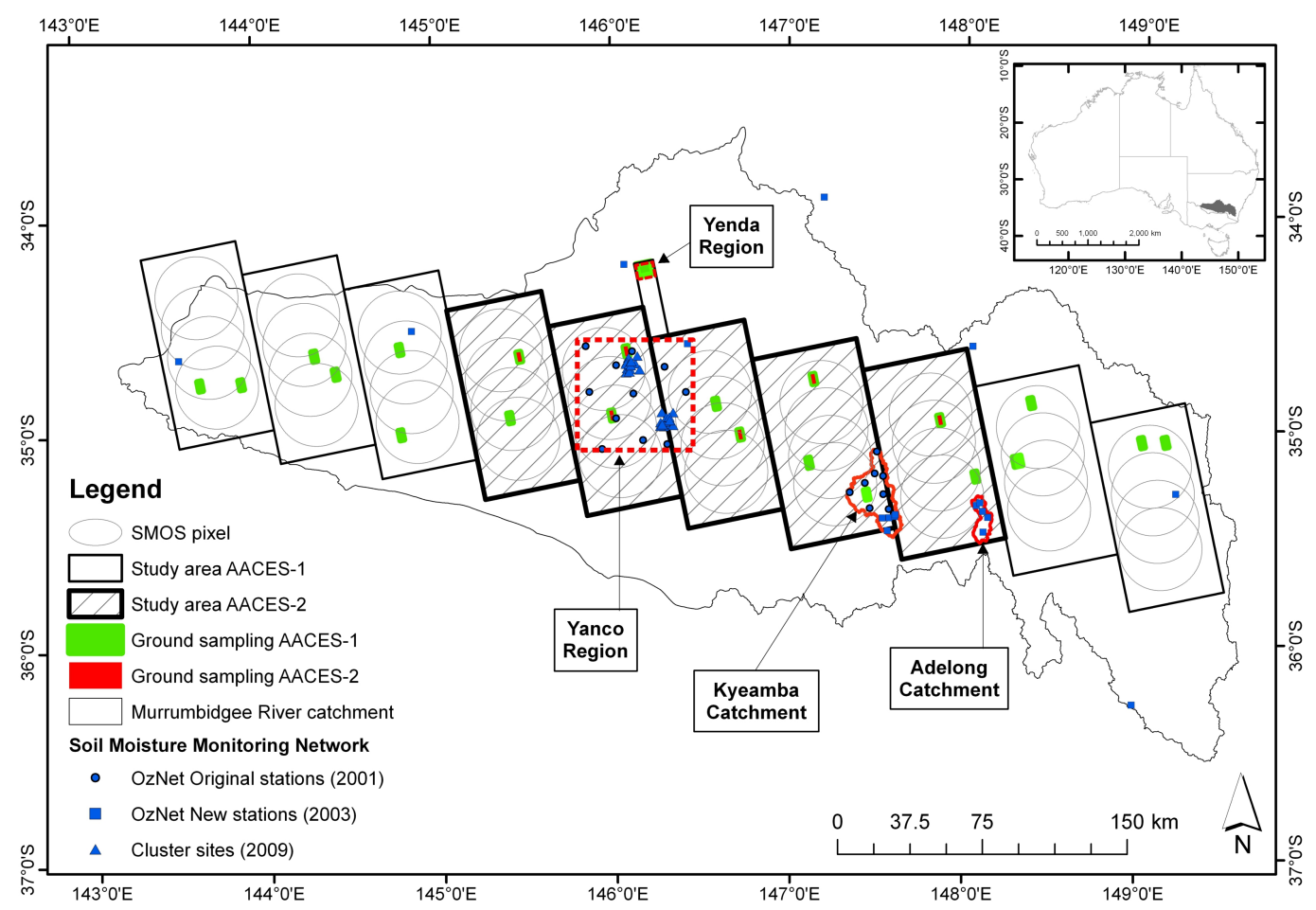

Fig. 1. Overview of the Murrumbidgee River catchment in Australia (inset), with AACES-1 covering all ten flight patches and AACES-2 focusing on the central half of the study area. SMOS footprints within each flight patch and the location of ground sampling activities as well as the existing long-term soil moisture network sites (OzNet) are indicated on the map.

activities representing a subset of the original transect that covered the central half (approximately $250 \times 100 \mathrm{~km}^{2}$ ). Data from the AACES-1 campaign had shown that this area was scientifically the most interesting, having a representative range of soil and vegetation conditions for the entire catchment. The airborne data acquisition started in the West of the Murrumbidgee River catchment and moved towards the East during each campaign. The AACES study area had been divided into ten flight patches of $50 \times 100 \mathrm{~km}^{2}$, each corresponding to a single flight day and aligned with the SMOS level 1C fixed ISEA (Icosahedral Snyder Equal Area projection) grid. Consequently, each patch contained a minimum of two independent (four overlapping) SMOS pixels of approximately $45 \mathrm{~km}$ size in their entirety.

The airborne measurements were conducted using a single-engine fixed-wing aircraft, which can carry a typical science payload of up to $250 \mathrm{~kg}$ in addition to a scientist and pilot. The typical cruising speed is about $150-270 \mathrm{~km} \mathrm{~h}^{-1}$ with a range of $9 \mathrm{~h}$ reserve ( $5 \mathrm{~h}$ for maximum payload). The aircraft ceiling is $3000 \mathrm{~m}$ or up to $6000 \mathrm{~m}$ with oxygen supply. The scientific equipment carried during experiments is installed in an underbelly pod and in the wingtips. The aircraft navigation and flight lines for the experiments, as well as instrument statuses are displayed via a computer screen in front of the scientist/co-pilot.

\subsection{Airborne instrumentation}

The airborne instruments operated in both AACES campaigns were the Polarimetric L-band Multi-beam Radiometer (PLMR), six thermal infrared sensors, and two sets of six multi-spectral sensors with four bands in the visible/nearinfrared and four bands in the shortwave infrared wavelength region (Table 1). The PLMR instrument consists of a flat-array antenna resulting in six beams which allow the land surface to be observed at three incidence angles $\left( \pm 7^{\circ}\right.$, $\pm 21.5^{\circ}$, and $\pm 38.5^{\circ}$ ). During each campaign the radiometer was mounted in the across-track or push-broom configuration, thus, scanning the earth surface at three angles to each side of the aircraft. The resulting $3 \mathrm{~dB}$ beam width of each beam corresponds to about $14^{\circ}$, producing a $6 \mathrm{~km}$ wide swath from a $3000 \mathrm{~m}$ a.g.l. flying height. The L-band radiometer operates at a frequency of $1.413 \mathrm{GHz}$ with a bandwidth of $24 \mathrm{MHz}$ and achieves a $40 \mathrm{~m}$ along-track ground sampling rate at approximately $72 \mathrm{~m} \mathrm{~s}^{-1}$ flight speed. Using a polarization switch, the PLMR is capable of dual-polarized measurements with an accuracy of higher than $2 \mathrm{~K}$ and $3 \mathrm{~K}$ for $\mathrm{H}$ - and V-polarization, respectively (Panciera et al., 2008). Moreover, the radiometer was removed from the aircraft and calibrated on a daily basis before and after each flight, using the sky as cold target and a blackbody box as warm target. The collected PLMR data were geolocated, with the local 


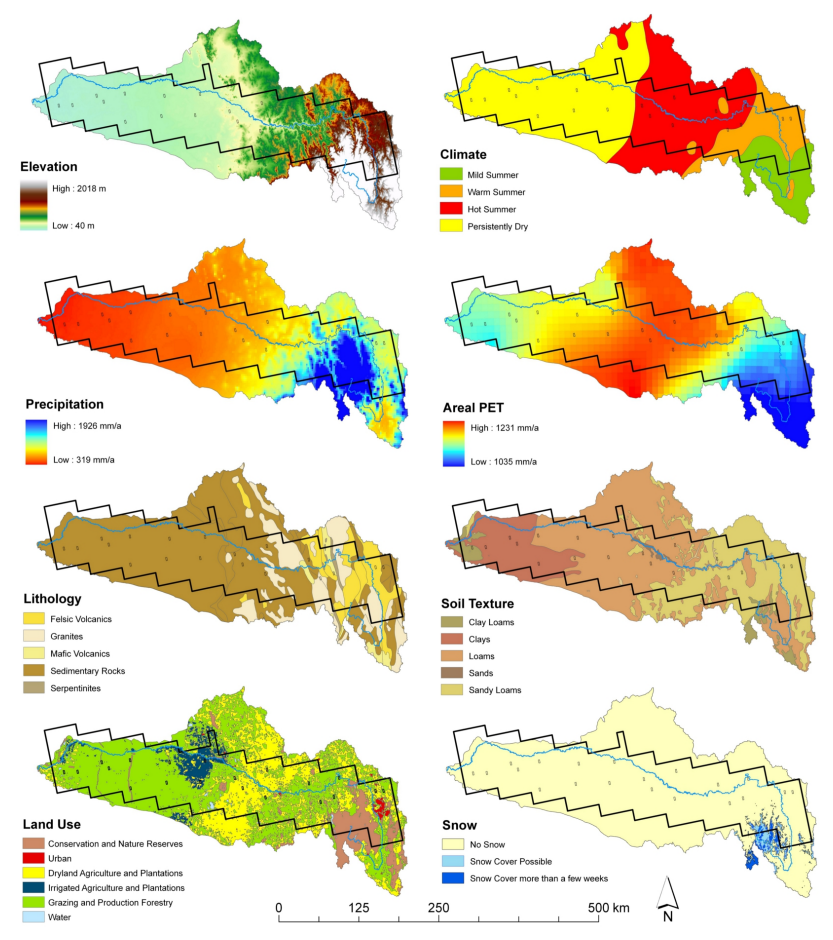

Fig. 2. Overview of the Murrumbidgee River catchment and its climatic, topographic and soil diversity. Overlain is the outline of the AACES study area with the course of the Murrumbidgee River and the location of the 20 focus farms, where the ground sampling activities took place. The spatial dataset is publicly available through Australian Bureau of Rural Science (2001, 2006) and Geoscience Australia (2008).

incidence angles and beam location calculated, taking into account ground topography, aircraft position and attitude information, which was all provided with each set of observations. The thermal infrared and multi-spectral sensors with a $15^{\circ}$ field of view were aligned with the PLMR beams, in order to have the same incidence angles and footprint sizes as the microwave radiometer.

\subsection{SMOS validation flights}

The airborne observations were classified into two flight types: (i) patch flights $(\mathrm{P})$ with each patch being mapped on a single day when full SMOS coverage was ensured for the specific patch, and (ii) transect flights (T) across the study area when the AACES study site was covered by SMOS in its entirety (Fig. 3). While the patch flights were only done once per patch and campaign, transect flights were flown several times during each campaign. The reasoning for this schedule was that the patch flights allowed the mapping of the whole AACES study area and hence the spatial variability in soil moisture across it, whereas the transect flights captured the temporal variation of the surface conditions throughout each field experiment.
Table 1. Multispectral and thermal infrared instrument characteristics.

\begin{tabular}{lcr}
\hline Sensor & MODIS band & Wavelength [nm] \\
\hline VIS/NIR (SKR 1850A) & & \\
\hline Channel 1 & 1 & $620-670$ \\
Channel 2 & 2 & $841-876$ \\
Channel 3 & 3 & $459-479$ \\
Channel 4 & 4 & $545-565$ \\
\hline SWIR (SKR 1870A) & & \\
\hline Channel 1 & 6 & $1628-1652$ \\
Channel 2 & - & $2026-2036$ \\
Channel 3 & 7 & $2105-2155$ \\
Channel 4 & - & $2206-2216$ \\
\hline Everest InterScience 3800ZL & & $8000-14000$ \\
\hline
\end{tabular}

The aircraft was based at a centrally located airport with the average flight time for a sampling day including the ferry and calibration flight segments being about $7 \mathrm{~h}$. A total of 85 mission hours were conducted during the first campaign and about 45 mission hours during the AACES2 campaign. The nominal flight altitude was $3000 \mathrm{~m}$ a.g.l. with the exception of alpine terrain, where the altitude was capped at $3400 \mathrm{~m}$ a.g.l. - in order to provide airborne data at a nominal $1 \mathrm{~km}$ spatial resolution. All flights were centred around 06:00 a.m. LST (20:00 UTC) to ensure aircraft observations were nearly coincident with SMOS overpasses. The typical time of the airborne mapping was between 04:3009:30 a.m. LST (17:30-22:30 UTC), excluding ferry flights to and from the airport. The availability of VIS/NIR/SWIR data is, therefore, limited by the illumination conditions of the earth, with a large portion of the patch flight completed before sunrise.

The airborne coverage of each patch flight was designed to include a $6 \mathrm{~km}$ overlap with the adjacent patch by repeating part of the last flight line of the previous sampling day. This guaranteed full coverage of the SMOS pixels while also providing continuity between the different flight days. Furthermore, changes in brightness temperature data compared to the previous flight day allowed an assessment of soil moisture and/or effective temperature variations. The individual flight lines within a single patch were $5 \mathrm{~km}$ apart from each other, achieving a $1 \mathrm{~km}$ overlap of the outer beams of two adjacent flight lines on both sides of the aircraft. This ensured as best as possible the complete coverage of the patch considering the possible impact of strong cross winds on attitude and heading of the aircraft.

In addition to the patch flights, there were at least two transect flights across the AACES domain when SMOS covered the entire study area (start and end of each campaign - plus one in the middle of AACES-1). These flights were designed in such a way that they would cover as many permanent monitoring stations and focus farms as practical. Thus, they 


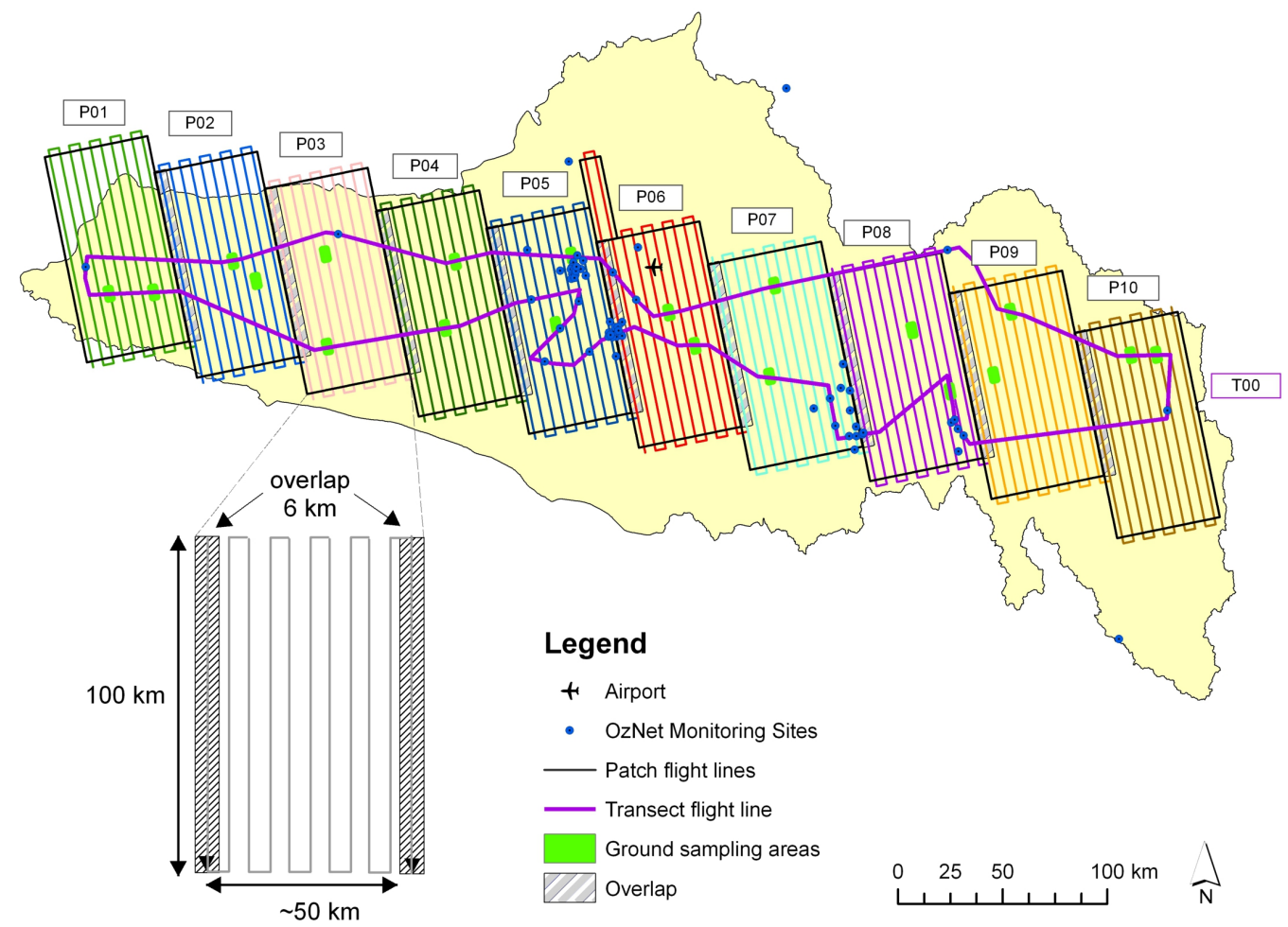

Fig. 3. Schematic of the airborne sampling strategy showing the flight lines for each individual patch flight (P) and the transect flight (T) across the AACES study area, with the latter designed to include as many ground sampling farms and OzNet monitoring sites as practical.

provided a snapshot of the soil moisture conditions across the entire AACES study area and allowed (i) an assessment of the temporal variability over the period of each individual campaign and (ii) a comparison with the European validation strategies. Furthermore, all transect and patch flights included a repeat of the first $\approx 12 \mathrm{~km}$ of the first flight line in order to assess temporal changes during the flight.

\subsection{Additional flight segments}

The ferry flights to and from the airport included at least one permanent monitoring station, and if practical, additional ground sampling farms located outside the target patch. Moreover, at the end of each flight period the aircraft flew at low level over Lake Wyangan, near Griffith, to calibrate the airborne L-band radiometer. The lake was continuously monitored for near-surface temperature and salinity throughout the campaigns. In addition, periodical in situ transect measurements of both parameters were undertaken in order to check for spatial gradients across the lake. Together with the airborne observations these data were used for the purpose of in-flight sensor calibration and data evaluation. Due to the early sampling and minimum altitude requirements for night flights, all calibration flights over the water storage target were conducted on the return flight only.

\section{Ground data description}

The ground monitoring was specifically designed to validate the aircraft observations at $1 \mathrm{~km}$ resolution and subsequently enable evaluation of the large scale SMOS products. Consequently, the ground team activities followed the aircraft across the study area from West to East during each campaign. The in situ data acquisition consisted of three components: (i) a permanent soil moisture profile monitoring network, (ii) temporarily installed monitoring stations, and (iii) intensive high resolution surface soil moisture and vegetation measurements. The ground sampling was concentrated on areas representative of the land use conditions within the respective airborne observed flight patch. Overall, these socalled focus farms captured the major climatic, topographic and soil texture variability across the entire AACES study area.

\subsection{Soil moisture monitoring network}

The OzNet hydrological monitoring network (www.oznet. org.au; Smith et al., 2012) has been operational since 2001 and comprises a total of 62 stations throughout the entire Murrumbidgee River catchment (see Fig. 1). The network was upgraded in 2003 by adding additional monitoring sites and in 2006 by including near-surface soil moisture sensors 

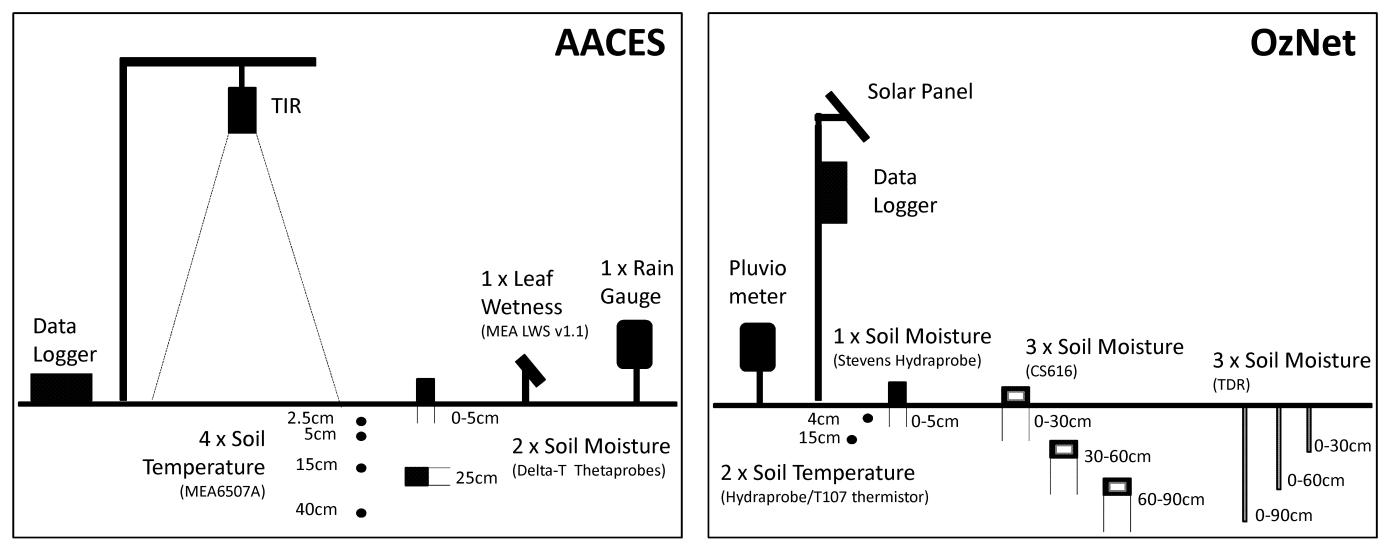

Fig. 4. Schematic of the temporary monitoring station instrumentation during the AACES field campaigns (left panel) and the permanent instrumentation at the new OzNet monitoring sites in the Murrumbidgee River catchment (right panel).

at all stations. In 2009, it was further augmented with two clusters of 12 supplementary stations within a $60 \times 60 \mathrm{~km}^{2}$ area focusing on the Yanco region in the western plains of the catchment. The network provides area-wide surface soil moisture measurements at $0-5 \mathrm{~cm}$ (or $0-7 \mathrm{~cm}$ for the older sites), using CS616 (CS615) water reflectometers, with the majority of stations additionally collecting soil moisture profile data across three depths $(0-30 \mathrm{~cm}, 30-60 \mathrm{~cm}$, and $60-$ $90 \mathrm{~cm}$ ). Supplementary parameters including (i) rainfall using a tipping bucket rain gauge, (ii) soil temperature $(2.5 \mathrm{~cm}$ and $15 \mathrm{~cm}$ ) and (iii) soil suction are also recorded (Fig. 4).

\subsection{Focus farm ground sampling}

The ground observations for AACES-1 (AACES-2) were concentrated on a total of 20 focus farms (6 focus farms), with two farms (one farm) per patch, distributed across the study area. The locations of the sampling farms were selected based on (i) the available background information including topography, land use, soil texture and (ii) logistics, including the accessibility and travel time from the ground team base. The focus farms were chosen to be fairly homogeneous and represent the locally dominant soil and vegetation type, while capturing the naturally existing variability within each patch. The $2 \times 5 \mathrm{~km}^{2}$ sized ground sampling farms were aligned along the aircraft flight lines and centred underneath the two inner PLMR beams in order to (i) guarantee aircraft coverage and (ii) allow ground truth data for a minimum of four independent PLMR pixels per farm.

In addition to the existing long-term soil moisture network operating across the Murrumbidgee River catchment, each focus farm was instrumented with two almost identical temporary monitoring stations. Due to limited equipment, these supplementary stations were moved across the study area according to the aircraft and ground sampling locations. The temporary stations were equipped with two soil moisture probes $(0-6 \mathrm{~cm}$ and $23-29 \mathrm{~cm})$, four soil temperature sensors
$(2.5 \mathrm{~cm}, 5 \mathrm{~cm}, 15 \mathrm{~cm}$, and $40 \mathrm{~cm})$, one tipping rain gauge and one leaf wetness sensor to determine the presence of dew observed during the satellite overpass (Fig. 4). Furthermore, one station per farm made thermal infrared measurements using a Raytek Thermalert TX (LT/LTP) to record the skin temperature of the (i) soil surface in the case of bare soil or (ii) canopy layer in the presence of vegetation. The TIR sensor used has a temperature range of $-18^{\circ} \mathrm{C}$ to $500^{\circ} \mathrm{C}$ and a spectral range from $8 \mu \mathrm{m}$ to $14 \mu \mathrm{m}$. The rational for setting up supplementary short-term stations on the focus farms was to verify three assumptions: (i) the effective temperature was relatively constant during the aircraft observations, (ii) the vegetation and soil temperature were in equilibrium around 06:00 a.m. LT (local time), and (iii) the soil moisture content within the top $5 \mathrm{~cm}$ did not change significantly throughout the course of the ground sampling. The temporary monitoring stations were ideally installed at least two days before the scheduled airborne sampling and spatial soil moisture measurements took place, as part of the focus farm reconnaissance activities. This ensured sufficient time for the soil temperature and soil moisture sensors to equilibrate within the partly disturbed soil column.

The focus farms were mapped with near-surface soil moisture measurements along six parallel lines of $5 \mathrm{~km}$ in length and $330 \mathrm{~m}$ spacing between them (Fig. 5). Along each of these transect lines a minimum of three soil moisture measurements (within a radius of $1 \mathrm{~m}$ ) of the top $5 \mathrm{~cm}$ were made every $50 \mathrm{~m}$ using the Hydraprobe Data Acquisition System (HDAS). By taking replicate measurements at each sampling point the effect of random errors at local scale was sought to be minimized. The HDAS system comprises a Global Positioning System (GPS), a hydraprobe soil moisture sensor and a Geographic Information System (GIS) that combines the information about location and soil moisture in a visual output (Panciera et al., 2009). The accuracy of the Stevens Water hydraprobe sensor implemented in the HDAS system has been determined to be $\pm 0.039 \mathrm{~m}^{3} \mathrm{~m}^{-3}$ on the 


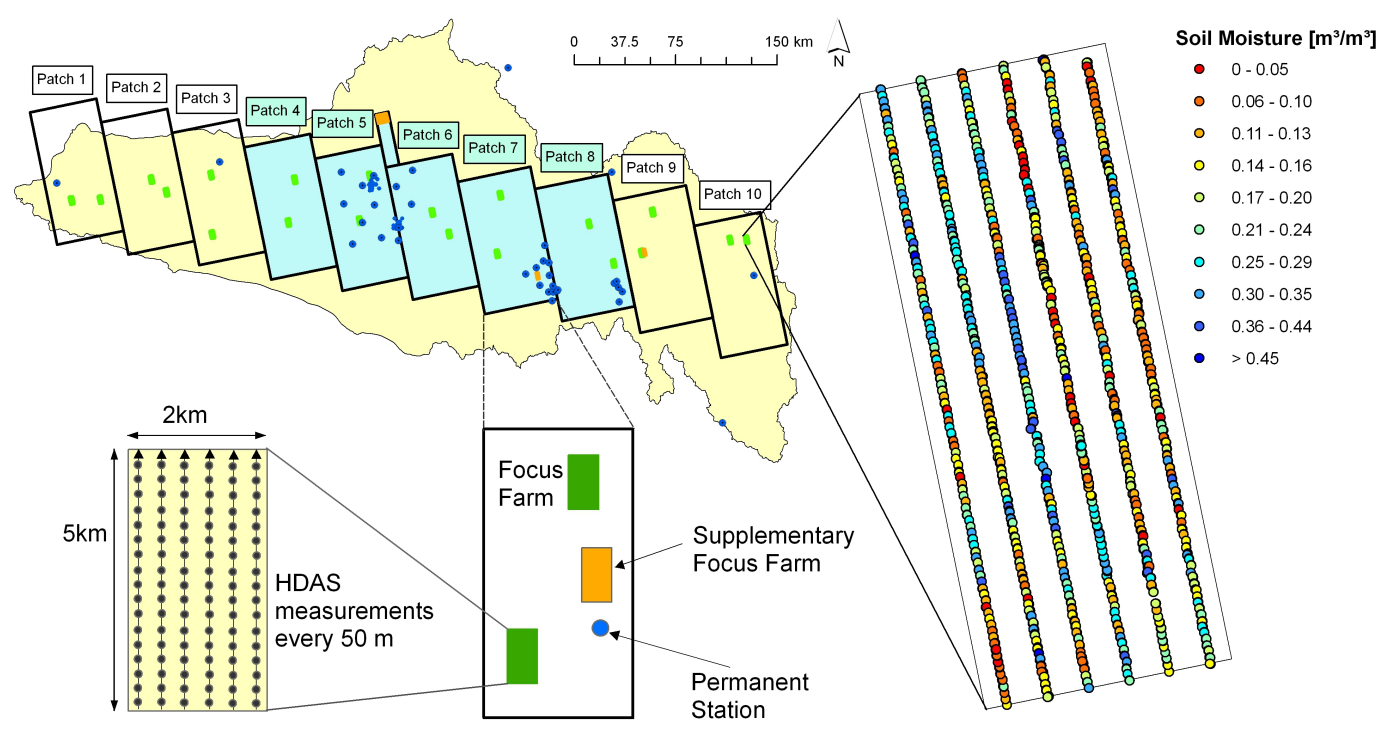

Fig. 5. Left panel: schematic of the ground sampling strategy concentrating on two focus farms per patch. Each focus farm was instrumented with two temporary monitoring stations and covered by six soil moisture sampling lines. Right panel: example of ground sampled, nearsurface soil moisture data using the HDAS system.

basis of 155 gravimetric soil samples collected across the Murrumbidgee River catchment during AACES. The estimated error is consistent with results from an earlier study (Merlin et al., 2008) that used a combined calibration approach with laboratory and field measurements. The archived gravimetric soil samples from the AACES campaigns have been further analysed for soil texture particle distribution to determine silt, sand and clay content (Table 2). Ancillary data including vegetation type and height, a visual estimate of rock cover fraction, dew presence and dew characteristics were also recorded for each HDAS sampling location and stored within the system. In the case of visible dew, leaf wetness samples were taken using pre-weighed paper towels to determine the actual amount of dew on the plant leaves (Kabela et al., 2009). All soil moisture and dew measurements were made as early in the morning as practical, while aiming for coincident data with the aircraft flights and SMOS overpasses at around 06:00 a.m. LT. The dew sampling, however, was limited to the time period of 05:3007:00 a.m. LST to focus the investigation on likely effects of dew on the L-band observations of SMOS and the airborne PLMR instrument. The $5 \mathrm{~km}$ soil moisture transects were generally completed between 05:30-10:00 a.m. (06:00 a.m.12:00 p.m.) for AACES-1 and (AACES-2) on a sampling day. Note, the longer sampling time during the AACES-2 winter campaign was due to (i) the moist soil conditions, which increased the cleaning time of the HDAS probe pins after each measurement, and (ii) the relatively dense canopy layer which significantly slowed down the pace of the sampler - especially when walking through mature canola crops.
On each focus farm, specific vegetation data including biomass and spectral surface samples were collected at multiple locations (Table 2). Vegetation water content (VWC) information is crucial in the soil moisture retrieval process and together with the spectral properties of the canopy has been shown to provide relationships for estimating the VWC and other vegetation variables. In general, all canopy measurements were undertaken for all the major vegetation types present on each focus farm within a $1 \mathrm{~km}^{2}$ box, which corresponded to one PLMR pixel. Across that box approximately five equally distributed sampling locations per vegetation type were chosen to characterise the dominant land cover. The actual vegetation data recorded at each focus farm included (i) leaf area index (LAI) using a LI-COR LAI-2000, (ii) hyper-spectral properties of the vegetation using a Fieldspec 3 instrument developed by ASD Inc., and (iii) destructive biomass samples from sampling locations previously observed with the LI-COR and ASD instruments. At each of the five sampling locations 3-5 individual LAI measurements were conducted within an approximate $10 \mathrm{~m}$ radius. Each LAI measurement consisted of five individual LAI readings: one above the canopy as a clear sky reference and four beneath the canopy (where possible half-way and near-soil). The final LAI measurement recorded was the average calculated from the combination of those readings.

The reflectance data were collected across a $5 \times 5 \mathrm{~m}^{2}$ area with a minimum of 25 ASD measurements on a regular grid of $1 \mathrm{~m}$ spacing, with a white reference measurement each 3-4 ASD measurements. In the case of rapid changing sky conditions white reference measurements were conducted before each individual ASD reading. The $5 \times 5 \mathrm{~m}^{2}$ 
Table 2. Characteristics of all focus farms sampled during AACES-1 and AACES-2 (shaded rows).

\begin{tabular}{|c|c|c|c|c|c|c|c|c|c|c|c|}
\hline \multirow[b]{2}{*}{ Patch } & \multirow[b]{2}{*}{ Farm } & \multicolumn{3}{|c|}{ Soil $^{\mathrm{a}}$} & \multicolumn{3}{|c|}{ Vegetation $^{\mathrm{b}}$} & \multicolumn{2}{|c|}{ Roughness $^{\mathrm{c}}$} & \multicolumn{2}{|c|}{ Soil Moisture $^{\mathrm{d}}$} \\
\hline & & Class & $\begin{array}{c}\text { Sand } \\
{[\%]}\end{array}$ & $\begin{array}{l}\text { Clay } \\
{[\%]}\end{array}$ & Type & $\begin{array}{c}\text { Dry Biomass } \\
{\left[\mathrm{kg} \mathrm{m}^{-2}\right]} \\
\min -\max \end{array}$ & $\begin{array}{c}\text { VWC } \\
{\left[\mathrm{kg} \mathrm{m}^{-2}\right]} \\
\min -\max \end{array}$ & $\begin{array}{l}\text { RMS } \\
\text { height } \\
{[\mathrm{mm}]}\end{array}$ & $\begin{array}{r}\text { Corr. } \\
\text { length } \\
{[\mathrm{cm}]}\end{array}$ & $\begin{array}{c}\text { Mean } \\
{\left[\mathrm{m}^{3} \mathrm{~m}^{-3}\right]}\end{array}$ & $\begin{array}{c}\text { Std } \\
{\left[\mathrm{m}^{3} \mathrm{~m}^{-3}\right]}\end{array}$ \\
\hline 1 & 1 & $\mathrm{LS}$ & 73 & 6 & grass & $0.12-0.37$ & $0.12-0.55$ & 5.36 & 11.23 & 0.05 & 0.02 \\
\hline 1 & 2 & SL & 52 & 14 & grass & $0.01-0.22$ & $0.01-0.20$ & 4.87 & 11.32 & 0.05 & 0.03 \\
\hline 2 & 3 & SL & 35 & 21 & grass & $0.14-0.35$ & $0.01-0.25$ & 3.10 & 7.23 & 0.04 & 0.02 \\
\hline 2 & 4 & SL & 38 & 24 & grass & $0.28-0.59$ & $0.10-0.19$ & 3.55 & 13.11 & 0.04 & 0.02 \\
\hline 3 & 5 & SL & 66 & 10 & grass & $0.17-0.68$ & $0.12-0.32$ & 2.77 & 8.18 & 0.04 & 0.02 \\
\hline 3 & 6 & SCL & 35 & 31 & grass & $0.22-0.51$ & $0.03-0.10$ & 4.72 & 12.88 & 0.04 & 0.02 \\
\hline 4 & 7 & SL & 63 & 11 & grass & $0.07-0.84$ & $0.04-1.01$ & 2.86 & 11.91 & 0.03 & 0.02 \\
\hline 4 & 7 & - & - & - & grass & $0.20-0.45$ & $0.83-3.16$ & 2.73 & 13.20 & 0.36 & 0.11 \\
\hline 4 & 8 & SCL & 42 & 31 & grass & $0.13-0.23$ & $0.02-0.13$ & 2.37 & 9.95 & 0.03 & 0.02 \\
\hline 5 & 9 & SL & 40 & 20 & grass & $0.01-0.26$ & $0.01-0.06$ & 3.48 & 10.34 & 0.09 & 0.07 \\
\hline 5 & 9 & - & - & - & grass & $0.11-0.29$ & $0.21-1.12$ & 3.06 & 11.52 & 0.28 & 0.10 \\
\hline 5 & 10 & LS & 68 & 9 & grass/crop & $0.20-0.57$ & $0.01-0.19$ & 4.15 & 11.76 & 0.08 & 0.06 \\
\hline 5 & 10 & - & - & - & crop/grass & $0.37-0.66$ & $1.48-3.55$ & 6.65 & 13.55 & 0.38 & 0.09 \\
\hline 6 & 11 & $\mathrm{LS}$ & 82 & 5 & grass/crop & - & - & - & - & 0.11 & 0.04 \\
\hline 6 & 12 & LS & 85 & 4 & grass/crop & - & - & - & - & 0.15 & 0.04 \\
\hline 6 & 12 & - & - & - & crop & $0.41-0.96$ & $2.30-5.46$ & 4.05 & 11.05 & 0.33 & 0.06 \\
\hline 7 & 13 & SL & 55 & 9 & grass & $0.02-0.16$ & $0.05-0.15$ & 7.06 & 12.45 & 0.11 & 0.05 \\
\hline 7 & 13 & - & - & - & crop/grass & $0.38-0.74$ & $1.11-2.22$ & 6.22 & 13.77 & 0.30 & 0.08 \\
\hline 7 & 14 & SL & 67 & 24 & crop/grass & $0.10-0.36$ & $0.01-0.21$ & 7.64 & 9.14 & 0.11 & 0.04 \\
\hline 8 & 15 & $\mathrm{LS}$ & 74 & 7 & grass & $0.05-0.50$ & $0.07-0.38$ & 6.07 & 11.47 & 0.29 & 0.05 \\
\hline 8 & 15 & - & - & - & crop & $0.26-0.58$ & $0.87-2.91$ & 3.74 & 11.21 & 0.26 & 0.06 \\
\hline 8 & 16 & $\mathrm{LS}$ & 92 & 1 & grass & - & - & 4.86 & 10.01 & 0.33 & 0.07 \\
\hline 9 & 17 & $\mathrm{LS}$ & 77 & 5 & grass & $0.18-0.35$ & $0.20-0.92$ & 5.73 & 16.21 & 0.21 & 0.06 \\
\hline 9 & 18 & $\mathrm{LS}$ & 74 & 4 & grass & $0.12-0.49$ & $0.28-1.24$ & 7.18 & 15.64 & 0.25 & 0.06 \\
\hline 10 & 19 & $\mathrm{LS}$ & 89 & 2 & grass & $0.21-0.35$ & $0.30-1.07$ & 5.77 & 15.97 & 0.25 & 0.08 \\
\hline 10 & 20 & $\mathrm{LS}$ & 80 & 3 & grass & $0.08-0.09$ & $0.03-0.05$ & 9.29 & 15.99 & 0.19 & 0.10 \\
\hline
\end{tabular}

${ }^{a}$ Class: $\mathrm{LS}=$ loamy sand, $\mathrm{SL}=$ silty loam, $\mathrm{SCL}=$ silt clay loam (based on the Australian soil texture classification standard); ${ }^{\mathrm{b}}$ type: in case of two major land cover types, the dominant vegetation is named first (VWC: Vegetation Water Content); ${ }^{c}$ average of slope corrected roughness profiles (RMS height: root mean square height; Corr. length: correlation length); ${ }^{d}$ average soil moisture and standard deviation (Std) measured with the HDAS system.

destructive sampling area was always located at the centre point of the grid. To assist with the data analysis, supplementary information including vegetation type and height, row spacing and direction, and photographs of the sky/cloud conditions as well as of the actual sample were taken for each sampling point. To ensure optimal spectral sampling conditions, the ASD vegetation measurements were made between 10:00 a.m.-02:00 p.m. LST. The LAI data were collected earlier at about 07:00-09:30 a.m. to reduce the effect of direct sunlight on the sensor. The destructive vegetation sampling took place by removing all organic matter within the sampling area and subsequently monitoring the weight loss through oven drying at $40^{\circ} \mathrm{C}$ until a constant weight was achieved. In addition to the vegetation sampling, the ground teams recorded at least three surface roughness profiles of $2 \mathrm{~m}$ length in North-South and East-West direction across each focus farm (Table 2). At each location a pin-profiler was positioned and levelled, and subsequently the height of each pin recorded manually as well as in a photograph. An overview of the total amount of ground data sampled during both AACES campaigns is given in Table 3 .
Table 3. Overview of total ground data collected during the AACES field campaigns.

\begin{tabular}{lrr}
\hline Measurement & AACES-1 & AACES-2 \\
\hline HDAS near-surface soil moisture & 36800 & 10800 \\
2 m surface roughness profile (NS, EW) & 48 & 16 \\
Gravimetric soil sample & 126 & 29 \\
LAI sample & 497 & 158 \\
Dew sample & 38 & 26 \\
ASD sample & 1575 & 175 \\
Destructive vegetation sample & 81 & 31 \\
\hline
\end{tabular}

In addition to the 20 AACES focus farms, three supplementary focus farms were included in the campaign dataset. These were operated by the CSIRO Griffith and the NSW Department of Environment and Climate Change in Wagga Wagga. While the ground sampling strategy was not identical to the general AACES experiment, similar measurements in terms of soil moisture, vegetation and gravimetric soil samples were collected and details are included in the online data archive. 

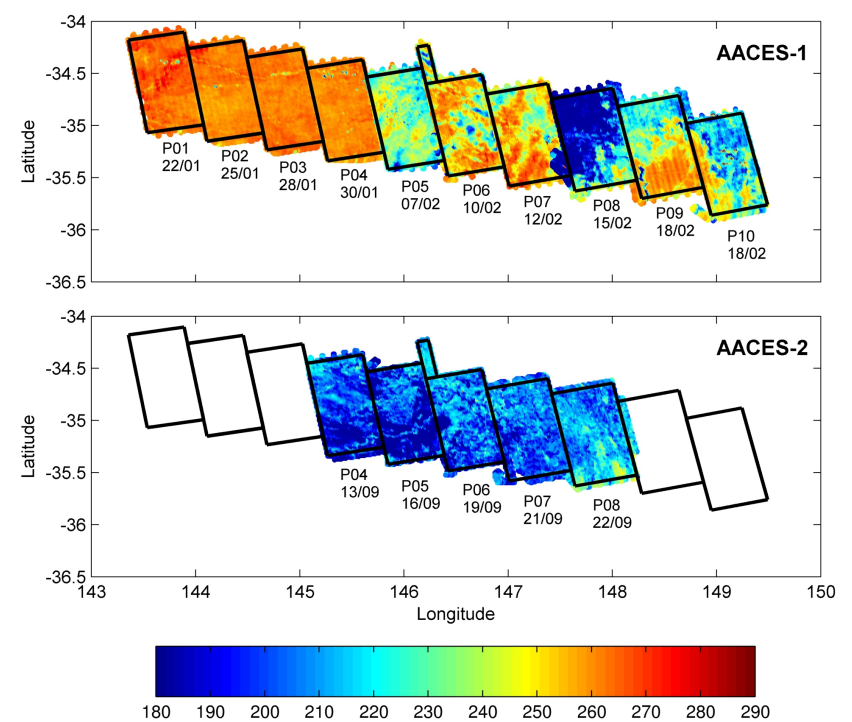

Fig. 6. Example of airborne L-band data collected at H-polarization during the summer (AACES-1) and winter (AACES-2) field campaigns with the brightness temperatures given in Kelvin. Note, each flight patch represents a single flight day.
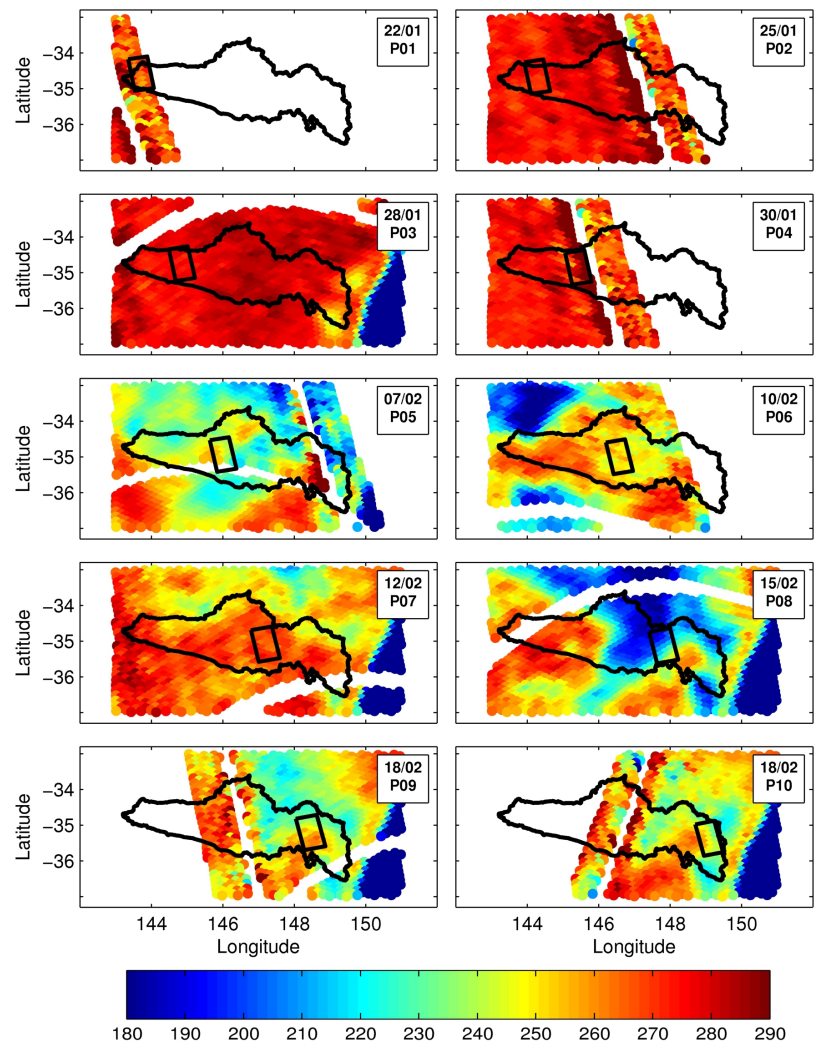

Fig. 7. Temporal and spatial patterns of H-polarized SMOS L1C brightness temperature data $[\mathrm{K}]$ collected during the summer field campaign (AACES-1). Overlain are the Murrumbidgee catchment boundary and the individual flight patch of that particular day, where airborne L-band data is available.
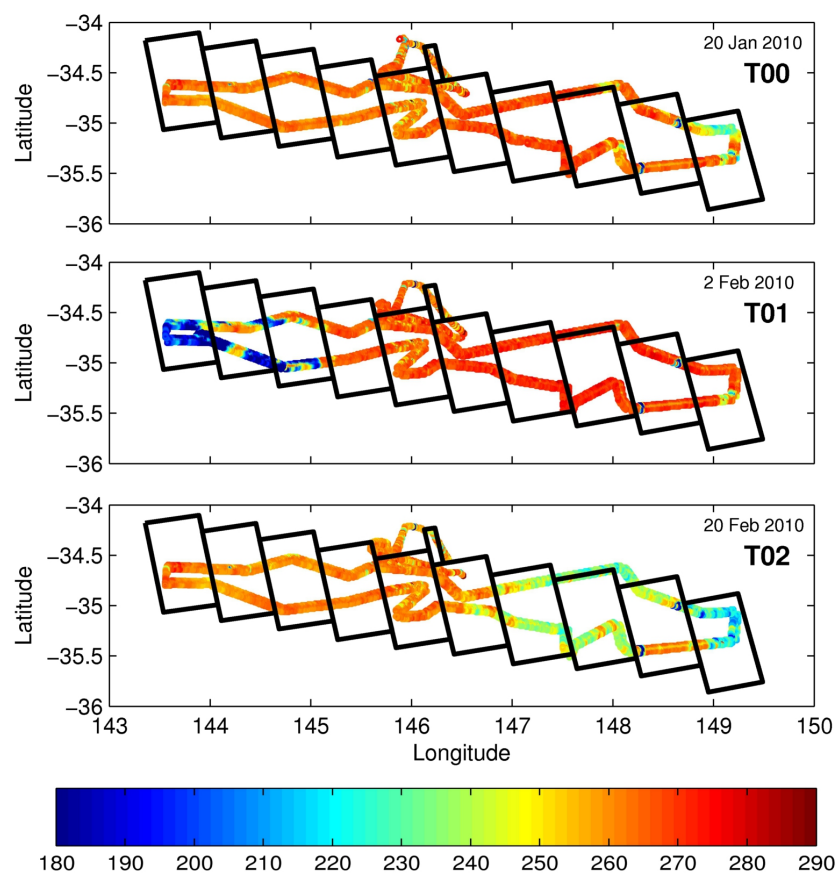

Fig. 8. Example of airborne L-band data collected at H-polarization during the AACES-1 campaign in transect flight mode (brightness temperatures given in Kelvin).

\section{Towards SMOS data validation}

During the AACES field experiments, significant changes in soil moisture conditions and land cover were observed (see Table 2). The AACES-1 campaign in summer 2010 commenced with daytime air temperatures above $30^{\circ} \mathrm{C}$ and very dry surface soil moisture conditions of approximately $0.05-0.10 \mathrm{~m}^{3} \mathrm{~m}^{-3}$. However, this changed to relatively moist $\left(0.25-0.35 \mathrm{~m}^{3} \mathrm{~m}^{-3}\right)$ and cool conditions due to a few significant rain events during the middle and towards the end of the campaign, with up to $140 \mathrm{~mm}$ rainfall on a single day. Moreover, the vegetation was relatively sparse (vegetation water content $0.1-0.6 \mathrm{~kg} \mathrm{~m}^{-2}$ ) and dominated by salt bushes in the western grazing areas, while the central and eastern parts of the study area were mainly characterised by low-vegetated pastures and mostly fallow or fresh ploughed farmland in cropping areas. In contrast, the AACES-2 campaign, undertaken during the Southern Hemisphere winter, provided relatively dense vegetation conditions (vegetation water content $0.1-5.2 \mathrm{~kg} \mathrm{~m}^{-2}$ ) with long pasture and mature crops (mainly wheat, barley, canola and lucerne) under moderate to wet surface soil moisture conditions $\left(0.2-0.4 \mathrm{~m}^{3} \mathrm{~m}^{-3}\right)$. Average air temperatures were $15^{\circ} \mathrm{C}$ throughout the campaign, with two days of rain having $10-20 \mathrm{~mm}$ each. 


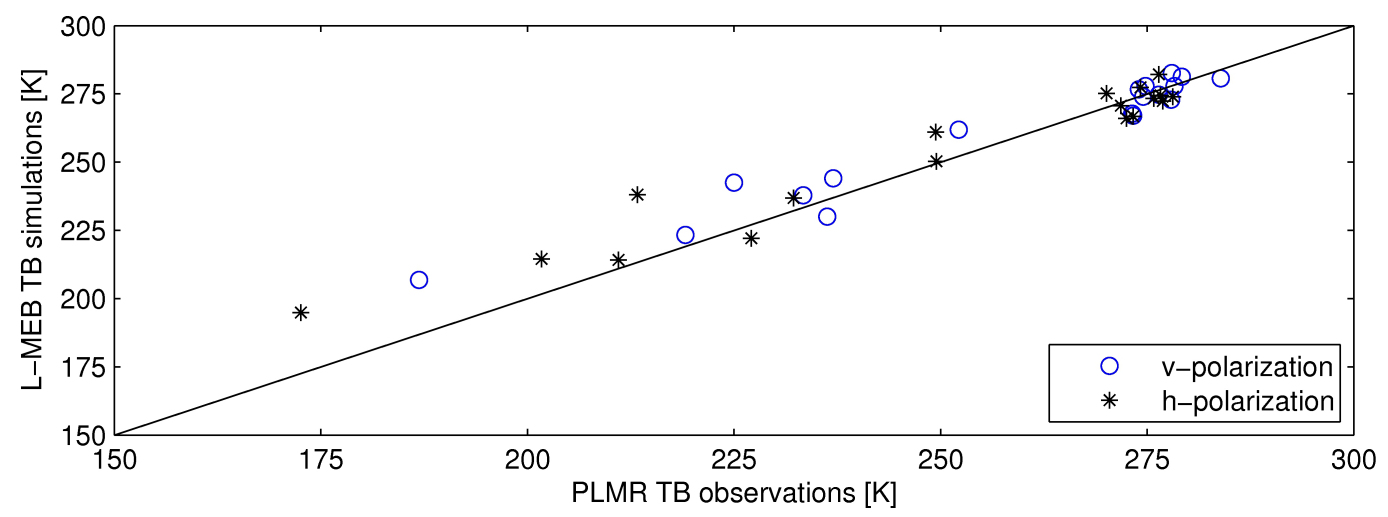

Fig. 9. Comparison of $1 \mathrm{~km}$ PLMR observations with L-MEB simulated brightness temperature data for AACES-1.

\subsection{Evaluation of L-Band brightness temperature patterns}

Figure 6 shows an example of the $1 \mathrm{~km}$ H-polarized PLMR observations collected during both AACES campaigns and normalized to $38^{\circ}$ incidence angle. For AACES-1, the intensive rain events that occurred during the middle (6-7 February) and end of the campaign (13-15 February) caused a significant drop in brightness temperatures (TB) in response to the sudden rise in soil moisture. Note that the course of the Murrumbidgee River can be clearly distinguished in the upper part of patches P01-P04, displaying low L-band observations for the river in comparison to the high brightness temperatures emitted by the surrounding dry soil surface. During the AACES-2 winter campaign with predominantly wet and cool conditions, the brightness temperatures mapped across the study area showed overall small variations. The comparison with the SMOS L1C brightness temperature data acquired during the AACES-1 campaign demonstrated that both temporal and spatial patterns of near-surface soil moisture are similar to those obtained by the airborne radiometer (Fig. 7). The evolution of the initially dry conditions present across the entire Murrumbidgee River catchment to wet conditions in the central and eastern parts of the study area is clearly depicted in the satellite data over the assigned flight patches. A detailed quantitative assessment of the SMOS L1C brightness temperature data with respect to the AACES dataset is the subject of a separate paper by Rüdiger et al. (2011).

Figure 8 presents the temporal patterns observed by the Lband sensor, when compared between the individual transect flights conducted during the AACES-1 summer campaign. The initial dry soil conditions across the study area (T00) for the western patches (P01-P03) showed a change in response to a local storm, causing lower brightness temperature measurements for those three patches on the second transect flight (T01). Conversely for the far eastern patch (P10) there was a dry down observed between T00 and T01. The transect flight at the end of the campaign (T02) captured (i) the moist soil conditions of the eastern study area after a few intense rainfall events, but also (ii) the dry down of the surface soil compared to the patch flight flown earlier over the precipitated area of $\mathrm{P} 01-\mathrm{P} 03$.

\subsection{Analysis of L-MEB performance}

The core algorithm in the SMOS soil moisture retrieval is the L-band Microwave Emission of the Biosphere (L-MEB) model (Kerr et al., 2011; Wigneron et al., 2007). A preliminary analysis of the AACES dataset has included tests of the L-MEB model performance for the range of topographic, land cover and soil moisture conditions observed during the field experiments. Based on the collected in situ ground data from all 20 focus farms, brightness temperature signals were simulated and subsequently compared against the airborne L-band measurements (Fig. 9). These results showed that for the range of brightness temperatures measured in AACES-1 (170-290 K), the L-MEB predictions with default parameters were close to the PLMR observations for dry conditions, such as those encountered during the beginning of the summer campaign with relatively high brightness temperatures responses. However, with increasing soil moisture and correspondingly lower brightness temperatures, the L-MEB algorithm tended to overestimate the emission, leading to significantly higher values of up to $25 \mathrm{~K}$ difference to that measured by the PLMR instrument. It is believed that this trend might be induced by the presence of water on the vegetation due to extensive rainfall events at those times. Consequently, for moderate-wet soil conditions, soil moisture estimates modeled by the L-MEB algorithm might be outside the SMOS target accuracy, if the source for such an offset is not considered. Further analysis of the AACES dataset will support a better understanding of the retrieval capabilities of SMOS, both in terms of the L1C brightness temperature as well as the derived L2 soil moisture product. 


\section{Summary}

The two AACES field experiments and associated datasets collected across the Murrumbidgee River catchment in Australia have been described. The study area, comprising more than 20 independent SMOS pixels in entirety, was extensively monitored under two seasonal conditions, summer (AACES-1) and winter (AACES-2) in 2010. The campaign sampling strategy included a combination of airborne Lband observations and extensive ground sampling activities coincident with SMOS overpasses. As the preliminary results in this paper and ongoing studies show, the AACES dataset is being used in various ways, such as validating (i) SMOS brightness temperature observations (level 1C product) (Rüdiger et al., 2011), (ii) SMOS derived soil moisture products (level 2), (iii) SMOS downscaled soil moisture products to $1 \mathrm{~km}$ resolution (Merlin et al., 2012) and (iv) the representativeness of the in situ monitoring network for soil moisture monitoring at $1 \mathrm{~km}$ and $45 \mathrm{~km}$ scale. Issues due to the low spatial resolution and the mixed land cover within a SMOS pixel can also be addressed by including the $1 \mathrm{~km}$ PLMR measurements and the ground data collected at the focus farms. Moreover, the AACES data allow a validation of the joint retrieval of ancillary parameters and soil moisture according to the SMOS approach using dual-polarized multiangle brightness temperature data. The much larger spatial and temporal scale of the AACES experiment compared to equivalent studies in Europe further enhances the ability to assess potential error sources that might be introduced by partial and/or transect sampling of SMOS pixels for validation purposes.

\section{Data availability}

The AACES dataset presented in this paper is available online at http://www.moisturemap.monash.edu.au/aaces. The website includes a detailed description of the two field campaigns (AACES-1 and AACES-2) and provides all the information required for data interpretation. A general overview of the Murrumbidgee River catchment, photographs, sampling techniques, as well as a copy of both field experiment plans and addenda are also given. Due acknowledgment in any publication or presentation arising from use of these data is required.

Acknowledgements. The authors would like to acknowledge all the farmers and landholders involved in the field experiments for their helpful cooperation and permission to access their properties. We further thank the Yanco Agricultural Research Institute (YAI) for providing accommodation, research and laboratory facilities. The AACES field experiments were a result of numerous collaborative efforts including Australian, Chinese, European and North American institutions. We wish to thank all participants that helped us to conduct these two very successful AACES campaigns (Channah Betgen, Simone Bircher, Tao Che,
Andrew French, Claire Gruhier, Xujun Han, Jon Johanson, Catherine Jolly, Olaf Klimczak, Jane Lai, Delphine Leroux, Xin Li, Mateusz Lukowski, Arnaud Mialon, Robert Pipunic, Ulrike Port, Dongryeol Ryu, Roosanne Schrooten, Sandra Slowinska, Mariette Vreugdenhill, Jun Wen, Anna Woijciga and Rodger Young), the student's supervisors (Richard de Jeu, Alexander Loew and Wojciech Marczewski), and the contributions made through additional ground sampling at the supplementary focus farms by the teams led by John Hornbuckle, Victor Shoemark and Gregory Summerell.

The AACES campaigns were funded through the Australian Research Council (DP0879212) as part of the MoistureMap project. The initial setup and maintenance of the Murrumbidgee monitoring network was funded by two ARC grants (DP0343778, DP0557543) and the CRC for Catchment Hydrology. The airborne instrumentation has been developed through ARC infrastructure grants (LE0453434, LE0560930). Further financial support for travel expenses was provided by ESA for the European participants and by the Australian Academy of Science for the Chinese visiting scientists.

Edited by: F. Pappenberger

\section{References}

Australian Bureau of Rural Science: Gridded rainfall data, based on the standard rainfall climatology (1961-1990), available at: http://www.bom.gov.au/climate/how/newproducts/ IDCraintempgrids.shtml (last access: August 2009), 2001.

Australian Bureau of Rural Science: Land Use of Australia, version 3 - 2001/2002, available at: http://adl.brs.gov.au/mapserv/ landuse (last access: August 2009), 2006.

Barré, H. M., Duesmann, B., and Kerr, Y. H.: SMOS: The mission and the system, IEEE T. Geosci. Remote, 46, 587-593, doi:10.1109/TGRS.2008.916264, 2008.

Cano, A., Millán-Scheiding, C., Wigneron, J., Antolín, C., Balling, J. E., Kruszewski, A., Saleh, K., Sœbjærg, S. S., Skou, N., and Lopez-Baeza, E.: The Mediterranean Ecosystem L-Band EXperiment over vineyards (Melbex-2), in: 10th Specialist Meeting on Microwave Radiometry and Remote Sensing for the Environment (MicroRad), 2008.

Cano, A., Saleh, K., Wigneron, J., Antolín, C., Balling, J. E., Kerr, Y. H., Kruszewski, A., Millán-Scheiding, C., Sœbjærg, S. S., Skou, N., and López-Baeza, E.: The SMOS Mediterranean Ecosystem L-Band characterisation EXperiment (MELBEX-I) over natural shrubs, Remote Sens. Environ., 114, 844-853, doi:10.1016/j.rse.2009.11.019, 2010.

de Rosnay, P., Calvet, J., Kerr, Y., Wigneron, J., Lemaître, F., Escorihuela, M. J., Sabater, J. M. N., Saleh, K., Barrié, J., Bouhours, G., Coret, L., Cherel, G., Dedieu, G., Durbe, R., Fritz, N. E. D., Froissard, F., Hoedjes, J., Kruszewski, A., Lavenu, F., Suquia, D., and Waldteufel, P.: SMOSREX: A long term field campaign experiment for soil moisture and land surface processes remote sensing, Remote Sens. Environ., 102, 377-389, doi:10.1016/j.rse.2006.02.021, 2006.

Delwart, S., Bouzinac, C., Wursteisen, P., Berger, M., Drinkwater, M., Martin-Neira, M., and Kerr, Y. H.: SMOS Validation and the COSMOS Campaigns, IEEE T. Geosci. Remote, 46, 695-704, doi:10.1109/tgrs.2007.914811, 2008. 
Dorigo, W. A., Wagner, W., Hohensinn, R., Hahn, S., Paulik, C., Xaver, A., Gruber, A., Drusch, M., Mecklenburg, S., van Oevelen, P., Robock, A., and Jackson, T.: The International Soil Moisture Network: a data hosting facility for global in situ soil moisture measurements, Hydrol. Earth Syst. Sci., 15, 1675-1698, doi:10.5194/hess-15-1675-2011, 2011.

Geoscience Australia: GEODATA 9 second DEM and D8: Digital Elevation Model version 3 and Flow Direction Grid 2008, available at: http://www.ga.gov.au/topographic-mapping/ digital-elevation-models/index.jsp (last access: August 2009), 2008.

Kabela, E. D., Hornbuckle, B. K., Cosh, M. H., Anderson, M. C., and Gleason, M. L.: Dew frequency, duration, amount, and distribution in corn and soybean during SMEX05, Agr. Forest Meteorol., 149, 11-24, doi:10.1016/j.agrformet.2008.07.002, 2009.

Kerr, Y. H., Waldteufel, P., Wigneron, J., Martinuzzi, J. M., Font, J., and Berger, M.: Soil moisture retrieval from space: The Soil Moisture and Ocean Salinity (SMOS) mission, IEEE T. Geosci. Remote, 39, 1729-1735, doi:10.1109/36.942551, 2001.

Kerr, Y. H., Waldteufel, P., Wigneron, J., Delwart, S., Cabot, F., Boutin, J., Escorihuela, M. J., Font, J., Reul, N., and Gruhier, C.: The SMOS Mission: New Tool for Monitoring Key Elements of the Global Water Cycle, Proc. IEEE, 98, 666-687, doi:10.1109/JPROC.2010.2043032, 2010.

Kerr, Y. H., Waldteufel, P., Richaume, P., Wigneron, J.-P., Ferrazzoli, P., and Gurney, R. J.: SMOS level 2 processor for soil moisture - Algorithm Theoretical Based Document (ATBD), Tech. Rep. ESA No.: SO-TN-ESL-SM-GS-0001, Issue 3.4, CESBIO, Toulouse, France, available at: http://www.cesbio.ups-tlse.fr/fr/ smos/smos_atbd.html (last access: 20 June 2012), 2011.

McKenzie, N., Jacquier, D., Ashton, L., and Cresswell, H.: Estimation of soil properties using the Atlas of Australian Soils, Tech. Rep. 11/00, CSIRO Land and Water, 2000.

Mecklenburg, S., Bouzinac, C., and Delwart, S.: Overview on calibration and validation activities for ESA's soil moisture and ocean salinity mission, in: IEEE International Geoscience and Remote Sensing Symposium (IGARSS), Vol. 3, The Institute of Electrical and Electronics Engineers, Inc. (IEEE), 3, III-85-III88, doi:10.1109/IGARSS.2009.5418111, 2009.

Merlin, O., Walker, J. P., Kalma, J. D., Kim, E. J., Hacker, J., Panciera, R., Young, R., Summerell, G., Hornbuckle, J., Hafeez, M., and Jackson, T. J.: The NAFE'06 dataset: Towards soil moisture retrieval at intermediate resolution, Adv. Water Resour., 31, 1444-1455, doi:10.1016/j.advwatres.2008.01.018, 2008.

Merlin, O., Rüdiger, C., Al Bitar, A., Richaume, P., Walker, J. P., and Kerr, Y. H.: Disaggregation of SMOS soil moisture over the AACES area with DisPATCh, IEEE T. Geosci. Remote, 50, 1556-1571, doi:10.1109/TGRS.2011.2175000, 2012.

Panciera, R., Walker, J. P., Kalma, J. D., Kim, E. J., Hacker, J., Merlin, O., Berger, M., and Skou, N.: The NAFE'05/CoSMOS Data Set: Toward SMOS Soil Moisture Retrieval, Downscaling, and Assimilation, IEEE T. Geosci. Remote, 46, 736-745, doi:10.1109/Tgrs.2007.915403, 2008.
Panciera, R., Allahmoradi, M., Merlin, O., Young, R., and Walker, J. P.: The Hydraprobe Data Acquisition System (HDAS) V.5: User Guide, Tech. rep., The University of Melbourne, 2009.

Panciera, R., Walker, J. P., Jackson, T., Ryu, D., Gray, D., Monerris, A., Yardley, H., Tanase, M., Rüdiger, C., Wu, X., Gao, Y., and Hacker, J.: The Soil Moisture Active Passive Experiments (SMAPEx): Towards Soil Moisture Retrieval from the SMAP Mission, submitted to IEEE T. Geosci. Remote, 2012.

Rüdiger, C., Walker, J. P., and Kerr, Y. H.: On the Airborne Spatial Coverage Requirement for Microwave Satellite Validation, IEEE Geosci. Remote S., 8, 824-828, doi:10.1109/LGRS.2011.2116766, 2011.

Saleh, K., Wigneron, J., Calvet, J., Lopez-Baeza, E., Ferrazzoli, P., Berger, M., Wursteisen, P., Simmonds, L. P., and Miller, J.: The EuroSTARRS airborne campaign in support of the SMOS mission: first results over land surfaces, Int. J. Remote Sens., 25, 177-194, doi:10.1080/0143116031000116444, 2004.

Smith, A., Walker, J. P., Western, A. W., Young, R., Ellett, K. M., Pipunic, R. C., Grayson, R. B., Siriwidena, L., Chiew, F. H. S., and Richter, H.: The Murrumbidgee Soil Moisture Monitoring Network Data Set, Water Resour. Res., online first: doi:10.1029/2011WR011749, 2012.

Walker, J. P., Rüdiger, C., Peischl, S., Ye, N., Bandara, R., Allahmoradi, M., Kerr, Y. H., Kim, E. J., Gurney, R. J., Barrett, D., and LeMarshall, J.: Australian Airborne Cal/val Experiments for SMOS (AACES) - Winter Campaign: Experiment Plan, Tech. rep., Monash University, available at: http://www. moisturemap.monash.edu.au/aaces/ (last access: 20 June 2012), 2010a.

Walker, J. P., Rüdiger, C., Peischl, S., Ye, N., Bandara, R., Allahmoradi, M., Ryu, D., Kerr, Y. H., Kim, E. J., Gurney, R. J., Barrett, D., and LeMarshall, J.: Australian Airborne Cal/val Experiments for SMOS (AACES): Experiment Plan, Tech. rep., The University of Melbourne, available at: http://www.moisturemap. monash.edu.au/aaces/ (last access: 20 June 2012), 2010b.

Whetton, P. H., Haylock, M. R., and Galloway, R.: Climate change and snow-cover duration in the Australian Alps, Climatic Change, 32, 447-479, doi:10.1007/BF00140356, 1996.

Wigneron, J., Kerr, Y. H., Waldteufel, P., Saleh, K., Escorihuela, M. J., Richaume, P., Ferrazzoli, P., de Rosnay, P., Gurney, R. J., Calvet, J., Grant, J. P., Guglielmetti, M., Hornbuckle, B., Mätzler, C., Pellarin, T., and Schwank, M.: L-band Microwave Emission of the Biosphere (L-MEB) Model: Description and calibration against experimental datasets over crop fields, Remote Sens. Environ., 107, 639-655, doi:10.1016/j.rse.2006.10.014, 2007. 